\title{
КЛЮЧЕВЫЕ НАПРАВЛЕНИЯ РАЗВИТИЯ ИНДУСТРИИ 4.0 В СОВРЕМЕННЫХ УСЛОВИЯХ ЦИФРОВИЗАЦИИ ЭКОНОМИКИ
}

\author{
(c) 2020 Бекбергенева Дина Евгеньева \\ кандидат экономических наук, доцент \\ Оренбургский филиал РАНХиГС, Россия, Оренбург \\ E-mail: Dinabekber@mail.ru
}

В статье выявлены ключевые направления развития Индустрии 4.0 в современных условиях цифровизации экономики, включая: цифровизацию и интеграцию всех цепочек создания стоимости, продуктов и услуг, построение цифровых бизнес-моделей взаимодействия с потребителями, квантовые скачки производительности промышленных предприятий. Особое значение уделено углублению взаимоотношений с ключевыми и компетентными потребителями на основе цифровых платформ, формированию цифровой культуры, обучению цифровым навыкам сотрудников и потребителей, а также обеспечению цифрового доверия со стороны всех стейкхолдеров, что требует изменения организационной культуры предприятий и стиля руководства.

Ключевые слова: Индустрия 4.0, циифровизация экономики, цепочки создания ценности, цифровые платформы, цифровое доверие

\section{Введение}

Термин «Индустрия 4.0» появился в 2011 году в Германии на Ганноверской ярмарке и представляет собой новый этап развития промышленности, который называют четвертой промышленной революцией. В отличие от предыдущего этапа Индустрии 3.0, когда основные усилия промышленных предприятий были направлены на автоматизацию оборудования и технологических процессов, основой нового этапа выступают инструменты цифровой экономики, такие как: анализ больших массивов данных и продвинутые алгоритмы, облачные сервисы, интеллектуальные датчики, 3D печать, «Интернет вещей», дополненная реальность, искусственный интеллект и персонификация взаимодействия с клиентами. Индустрия 4.0 включает широкий спектр новых технологий для создания ценности и позволяет очень быстро и качественно создавать, анализировать и передавать данные без потерь.

\section{Степень исследования}

В научной литературе понятие Индустрия 4.0 новое, к единому пониманию содержания этого понятия еще не пришли, но в некоторых источниках представлены интересные подходы $[3,4,6]$. Клаус Шваб, основатель и президент Всемирного экономического форума в Женеве выделяет три основных блока Индустрии 4.0: физический, цифровой и биологический [5]. В отечественной литературе существуют исследования технологий проектно-производственной деятельности предприятий в условиях Индустрии 4.0 [8, 2], изучаются стадии, которые проходит каждое промышленное предприятие в процессе перехода от Индустрии 3.0 к Индустрии 4.0 [9]. Особый интерес вызывают исследования Шукалова А.В., Заколдаева Д.А., ЖариноваИ.О., в которых представлено сравнение систем управления на промышленном производстве с позиций Индустрии 3.0 и Индустрии 4.0 [7, 1]. Но, несмотря на имеющиеся научные исследования, считаем, что многие аспекты содержания концепции Индустрии 4.0 требуют уточнения, потому целью данного исследования выступило выявление ключевых направлений развития нового этапа промышленной революции в условиях цифровизации экономики.

\section{Результаты исследования}

Изучив подходы разных авторов, сформулируем дефиницию Индустрия 4.0 следующим образом: - это система социально-экономических отношений, возникающих в процессе максимальной цифровизации и автоматизации промышленного производства на основе использования современных киберфизических, облачных и аддитивных технологий, возможностей искусственного интеллекта и приемов обработки больших объемов данных с последующим формированием глобальной промышленной сети бизнес-процессов, продуктов и услуг. На рисунке 1 представлены основные направления развития Индустрии 4.0, выявленные автором.

Рассмотрим характеристику ключевых на- 


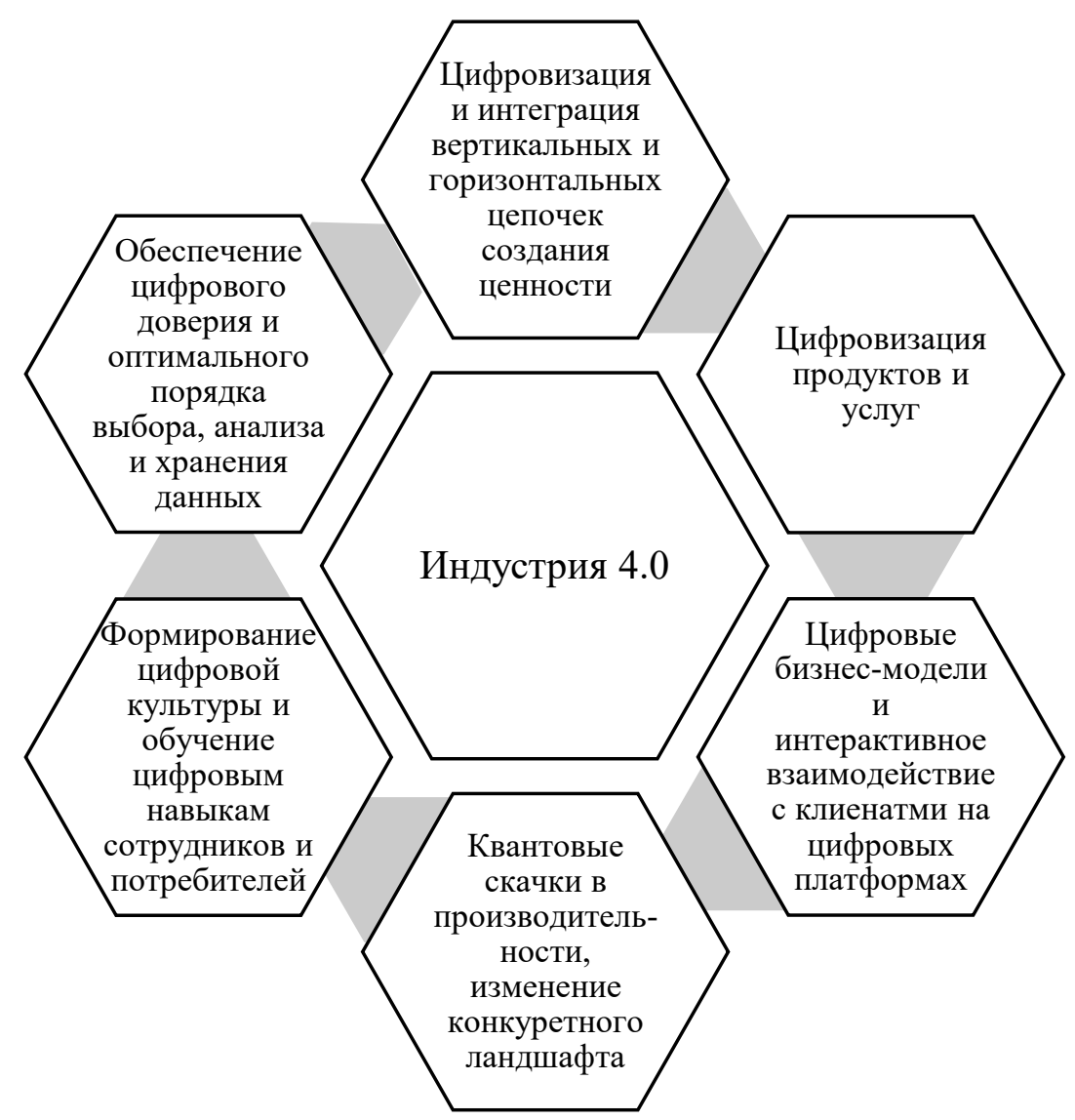

Рисунок 1. Ключевые направления развития Индустрии 4.0 (составлено автором)

правлений развития Индустрии 4.0 в современных условиях цифровизации экономики:

1) цифровизация и интеграция вертикальных и горизонтальных цепочек создания ценности. Вертикальная цифровизация происходит внутри предприятия, затрагивая все бизнеспроцессы, начиная с разработки идеи продукта или услуги и заканчивая послепродажным обслуживанием покупателей. Единая информационная система должна включать всю информацию о проводимых операциях по закупке материала, движении ресурсов, выполнении проектов, создании продуктов, транспортировки их между цехами или отделами, хранении на складах, движении готовой продукции в торговом зале или между торговыми представительствами, пред- и послепродажном обслуживании покупателей. Все данные доступны заранее определенному кругу лиц из любой точки входа в систему в режиме реального времени, поддерживаются дополненной реальностью и оптимизируются в интегрированной сети. Горизонтальная цифровизация охватывает взаимодействие факторов и субъектов микросреды предприятия, интегри- руя в единую информационную систему в реальном времени все операции поставщиков, конкурентов, партнеров, посредников, потребителей, акционеров и других стейкхолдеров по всей цепочке создания ценности. Данное направление развивается медленнее, чем вертикальная цифровизация, так как требует сбалансированных и доверительных взаимоотношений всех субъектов внешних бизнес-процессов;

2) цифровизация продуктов и услуг, входящих в бизнес-портфель предприятия. Добавление интеллектуальных датчиков или коммуникационных устройств помогает отслеживать состояние и динамику качественных или количественных характеристик продукции длительного срока эксплуатации и увеличивать удовлетворенность потребителей за счет снижения сбоев и поломок в работе технически сложных изделий. Цифровизация услуг предполагает проведение онлайн обучения, консультаций, реализации функций управления проектами и предприятиями, что особенно востребовано на рынке В2В. Улучшение понимания клиентов с помощью интеллектуального анализа данных 
также позволит компаниям лучше сосредоточиться на дополнительном высокодоходном бизнесе;

3) цифровые бизнес-модели и интерактивное взаимодействие с ключевыми и компетентными клиентами на основе управляемых данными сервисов и интегрированных платформенных решений. По мере развития Индустрии 4.0 традиционная модель производства продуктов, предлагаемых производителем на рынок исходя только из своих возможностей, будет исчезать, и появится другая модель, когда клиенты тесно связаны отношениями сотрудничества с производителями. Углубление отношений с клиентами посредством совместного создания и настройки продукта, цифровой интеграции с заказчиком и новых технологических возможностей для приближения производства к заказчику, например с помощью 3D-печати, позволят повысить степень индивидуализации или даже кастомизации продукции. Использование цифровых платформ позволит упростить взаимодействие с клиентами, предоставляя им комплексные цифровые решения в рамках одной цифровой экосистемы. При этом промышленное предприятие, производящее определенное оборудование, с помощью ресурсов собственной или арендуемой цифровой платформы сможет обеспечить потребителей всеми смежными с основным продуктом предложениями: доставка оборудования, страхование груза, обучение сотрудников, диагностика возможных нарушений в работе, мониторинг показателей работы, будущие модернизации и постоянное интерактивное общение с покупателями. Это указывает на возможность ориентации на клиента как на основного источника необходимых изменений в цепочках создания стоимости продуктов и услуг. В идеале развития Индустрии 4.0 все промышленные предприятия должны будут иметь собственные цифровые платформы для организации взаимоотношений с конечными клиентами или интегрироваться с известными платформами, которые позволят им эффективно обращаться к конечным клиентам. Цифровая платформа - это связующее звено процесса обмена информацией и взаимозаменяемых технологий, которое позволяет широкому кругу поставщиков и клиентов беспрепятственно взаимодействовать;

4) цифровизация бизнеса приведет к квантовым скачкам в производительности компаний, которые успешно внедряют Индустрию 4.0, что коренным образом может изменить конкурентный ландшафт и принесет фундаментальные изменения в существующие отрасли промышленности. Цифровизация экономики приведет к снижению транзакционных издержек, операционных расходов и повышению эффективности деятельности. Например, компании могут переходить к интегрированному прогнозированию и планированию производства за счет внедрения систем объединения всех данных, используемых на предприятий,- от простых датчиков до ERP-систем с информацией от партнеров по горизонтальной цепочке создания стоимости, такой как уровень запасов или изменения потребительского спроса. Интегрированное планирование производства повышает эффективность использования активов и время движения продукции по территории предприятия. Другим примером является прогнозная оценка характеристик оборудования для оптимизации графиков ремонта и технического обслуживания и повышения безотказной работы технологических линий и отдельных станков;

5) формирование цифровой культуры и обучение цифровым навыкам сотрудников организаций. Чтобы стимулировать цифровую трансформацию промышленным компаниям необходимо развивать надежную корпоративную цифровую культуру и следить за тем, чтобы изменения происходили под четким руководством. Сотрудники должны полностью понимать стратегические цели и задачи руководства, особенно в части реализации инновационных решений, так как неприятие или даже отторжение принципов новой цифровой культуры сотрудниками организации может негативно сказаться на восприятии цифровых решений конечными потребителями. Потому самые большие проблемы в процессе цифровой трансформации предприятия могут быть связаны не с адаптацией к внешним факторами, а с перестройкой внутренней среды функционирования предприятия, в том числе с формированием новой организационной культуры. Одним из решений данной проблемы может быть использование аутсорсинга, привлечение высококвалифицированных в цифровом пространстве сотрудников извне. При этом, если не сформировать цифровые компетенции у сотрудников компании, то результатом может стать слияние или поглощение более развитой в этом вопросе компанией; 
6) обеспечение цифрового доверия и оптимального порядка выбора, анализа и хранения данных. По мере расширения цифровых экосистем возрастает важность установления высокого уровня цифрового доверия потребителей, сотрудников и стейкхолдеров, подкрепляемого прозрачностью действий, отсутствием сокрытия информации, целостностью и указанием источника происхождения собственных и сторонних данных. Для решения этих задач необходимо иметь в наличии надежную систему управления рисками и обеспечения целостности и безопасности данных, что поможет компаниям избежать нарушений и лучше управлять сбоями в работе. Аналитика данных и цифровое доверие являются основой Индустрии 4.0, работа с данными лежит в основе четвертой промышленной революции, но массово растущий поток информации приносит мало пользы без правильных методов анализа. Растущее число интеллектуальных датчиков, встроенных систем и подключенных к Интернету вещей устройств, а также цифровизация горизонтальных и вертикальных сетей цепочек создания ценности приводят к огромному непрерывному потоку данных, которые поступают из нескольких источников и в разных форматах, что требует новых подходов к их обработке и комбинации внутренних данных с данными из внешних источников. И с таким большим количеством источников информации компании должны принимать строгий, проактивный подход к безопасности данных и работать над формированием цифрового доверия всех участников экономических отношений. Но нужно понимать, что результаты анализа данных с помощью искусственного интеллекта являются инструментом для принятия решений, в не полной заменой здравого смысла и аналитического суждения со стороны руководства компании.

\section{Заключение}

Таким образом, для получения дополнительных доходов прогрессивные компании внедряют эволюционные и революционные инновации, расширяя свой бизнес-портфель за счет продук- тов и услуг с цифровыми функциями. Прорывному росту доходов промышленных предприятий могут способствовать цифровые услуги, основанные на анализе данных, или комплексные цифровые решения, такие, как датчики на оборудовании, автоматические устройства подключения, мультифункциональное программное обеспечение, мобильные приложения или комплексные производственные исполнительные системы, обслуживающие целую экосистему клиентов. Кроме того, промышленные компании должны инвестировать средства в обучение сотрудников и стимулирование необходимых организационных изменений. Скорость трансформации цифровых технологий в доходный товар зависит от коэффициента цифрового интеллекта организации, особенно от того, насколько хорошо ее руководство, генеральный директор, технический директор или директор по развитию планируют и реализовывают цифровую трансформацию на предприятии. Также важным является уровень цифровой квалификации сотрудников, которым необходимо в соответствии с их функциональными обязанностями внедрять цифровые процессы и услуги. Новые цифровые экосистемы могут эффективно функционировать только в случае наличия цифрового доверия всех вовлеченных в процесс изменений участников, которое может быть сформировано при обеспечении предприятием безопасности данных, каналов коммуникаций, интеллектуальной собственности, что требует значительных инвестиций и четкого руководства.

Индустрия 4.0 является вектором экономического развития всех промышленных предприятий в условиях развития цифровой экономики. Для эффективной трансформации бизнес-процессов предприятия в условиях и вызовах новой промышленной революции, необходимо определить ключевые направления вложения материальных, информационных и трудовых ресурсов и усилий, что и было показано в данной статье.

\section{Библиографический список}

1. Гурьянов А.В., Заколдаев Д.А., Жаринов И. О. Маршруты сквозного автоматизированного проектирования документации изделий приборостроения на предприятиях «Индустрии 3.0» и «Индустрии 4.0» // Вопросы оборонной техники. Серия 16: Технические средства противодействия терроризму. 2018. № 1-2 (115-116). C. $167-174$. 
2. Гуторович О. В. Четвертая промышленная революция и ее возможные последствия // Дискурс. 2018. № 6. С. 11-17.

3. Ингеманссон А.Р. Актуальность внедрения концепции «Индустрия 4.0» в современное машиностроительное производство // Наукоемкие технологии в машиностроении. 2016. Т.1. № 7. С. 45-48.

4. Левенцов В.А., Радаев А. Е., Николаевский Н. Н. Аспекты концепции «Индустрия 4.0» в части проектирования производственных процессов // Научно-технические ведомости Санкт Петербургского государственного политехнического университета. Экономические науки. 2017. Т.10. № 1. С. 19-31.

5. Шваб К. Четвертая промышленная революция / пер. с англ. Москва: Эксмо, 2016. 138 с. Режим доступа: http://ncrao.rsvpu.ru/sites/default/files/library/ k._shvab_chetvertaya_promyshlennaya_revolyuciya_2016.pdf (дата обращения 22.04.2020).

6. Шеве Г., Хюзиг С., Гумерова Г.И., Шаймиева Э.Ш. От Индустрии 3.0 к Индустрии 4.0: основные понятия, измерения и компоненты Индустрии 4.0 // Инвестиции в России. 2019. № 9 (296). С. 32-40.

7. Шукалов А.В., Заколдаев Д.А., Жаринов И. О. Алгоритмы проектирования механосборочного производства предприятий Индустрии 3.0 и Индустрии 4.0 // Вопросы оборонной техники. Серия 16: Технические средства противодействия терроризму. 2018. № 3-4 (117-118). С. 148-154.

8. Шукалов А.В., Заколдаев Д. А., Жаринов И. О. От индустрии 3.0 к индустрии 4.0: обзор инноваций // Вопросы оборонной техники. Серия 16: Технические средства противодействия терроризму. 2018. № 11-12 (125126). C. $153-159$.

9. Schuh G., Anderl R., Gausemeier J., Ten Hompel M., Wahlster W. Industrie 4.0 Maturity index. Managing the digital transformation of companies (acatech STUDY), Munich: Herbert Utz Verlag. 2017. 60 p. 